\title{
COX-2 inhibitors in breast cancer
}

\author{
N. L. P. Barnes, N. J. Bundred \\ Department of Academic Surgery, South Manchester University Hospital, Manchester, UK.
}

\begin{abstract}
The cyclooxygenase (COX) enzymes catalyse the rate-limiting step of conversion from arachidonic acid to prostaglandins (PGs). The enzyme exists in two isoforms COX-1 and COX-2. The inducible COX-2 isoform has been shown to be present in up to $80 \%$ of breast cancers, high expression correlating with low rates of apoptosis, increased angiogenesis and poor prognosis. Both non-steroidal anti-inflammatory drugs (NSAIDs) and selective inhibitors to COX-2 have been associated with anti-tumoural properties, decreasing the rates of tumour growth, increasing apoptosis and inhibiting angiogenesis. A variety of cellular mechanisms have been suggested, but the exact mechanisms of action remain unclear. COX-2 inhibitors have the potential to be used either alone, or in combination with other agents such as aromatase inhibitors (Als), monoclonal antibodies (i.e. trastuzumab) or chemotherapeutic agents as novel therapeutic strategies against breast cancer. However the potential cardiac toxicity of the COX-2 selective compounds needs to be fully addressed, with the future development of either safe dosing regimes or new compounds.
\end{abstract}

Keywords: Breast; Cancer; Cyclooxygenase; Treatment

\section{Introduction}

\section{The cyclooxygenase enzymes}

The cyclooxygenase (COX) enzymes are involved in the oxidative rate-limiting step in the transformation of arachidonic acid into prostaglandin (PG)H2 via PGG2 (which is the substrate for all the other specific $P G$ synthesases, including $P E_{2}$, prostacyclin and thromboxanes). The two main COX isoforms, COX-1 and COX-2 [1] were first demonstrated in the early 1990s [2,3] COX-1 is constitutively expressed in most tissues [4], and is responsible for physiological housekeeping functions such as platelet aggregation and gastric cytoprotection [5]. COX-2 expression is induced by a wide range of growth factor and oncogenes [6], including the Type 1 Tyrosine-kinase

Correspondence to: N. J. Bundred, Department of Academic Surgery, South Manchester University Hospital, Education and Research Centre 2nd Floor, Southmoor Road, Wythenshawe, Manchester, M23 9LT, UK. E-mail: bundredn@man.ac.uk; Tel: +44 161291 5859; Fax: +44 161291 5860

Received 09/05/05

Accepted 16/06/05

First published online 11/11/05

$\mathrm{BCO} / 403 / 2005 / \mathrm{FO}$ human epidermal growth factor receptor HER-2/neu (c-erbB2), the NFKB and NFIL6 inflammation pathways. Over-expression of COX-2 has been detected in over $70 \%$ of in situ and invasive breast tumours [7] in addition to a wide variety of solid epithelial tumours including the colon, lung, prostate, skin, oesophagus, pancreas and bladder [8]. Over-expression of COX-2 has been shown to promote angiogenesis [9] and cell proliferation $[7,10]$ and inhibit apoptosis [11]. In invasive breast cancer, high levels of COX-2 expression are associated with a significantly poorer diseasefree survival compared with patients whose tumours express low or no COX-2 [12], and high levels of COX-2 correlate with an increased risk of recurrence in the pre-invasive breast cancer ductal carcinoma in situ (DCIS) [13].

\section{COX inhibitors}

Vane demonstrated the anti-inflammatory properties of non-steroidal anti-inflammatory drugs (NSAIDs) in 1971 [14]. These inhibitors show action against both COX-1 and COX-2 isoforms. Their duration of use is still limited due to their gastrointestinal side effects 
including peptic ulceration secondary to inhibition of COX-1. Therefore more recently there has been development of selective inhibitors. The COX-2 selective inhibitors were initially licensed for use in osteoarthritis. Their specificity lies with the fact that COX-1 and COX-2 are structurally different. COX-2 has a side pocket (thought to be the binding site) which is not present in the COX-1 enzyme [15]. This large side pocket allows bulkier specific inhibitors to attach to COX-2, which could not attach to the smaller binding site on COX-1 $[16,17]$. It was believed these selective inhibitors would not show the COX-1 related side effects (including gastric ulceration). The degree of avoidance of these COX-1 mediated side effects is still contentious and the overall safety of the COX-2 specific inhibitors has recently been brought in to question and is discussed later.

\section{COX inhibitors and cancer}

The anti-tumour effects of the both the non-selective and selective COX inhibitors have been demonstrated. Results of the women's health initiative (WHI) observational study found that regular users (more than two tablets a week for 5-9 years) of NSAIDs showed a $21 \%$ reduction in breast cancer relative risk (RR) 0.79; 95\% confidence interval (Cl) 0.60-1.04 and long-term use ( $>10$ years) a $28 \%$ reduction $R R$ $0.72 ; 95 \% \mathrm{Cl} 0.28-0.96$ [18] compared to non-users. In animal models aspirin, indomethacin, ibuprofen and diclofenac are among the non-selective inhibitors that have shown anti-cancer effects, including reduction of tumour growth, cell proliferation, apoptosis and angiogenesis. The proof of principle work regarding COX-2 inhibition and cancer was undertaken with colorectal cancer. In familial adenomatous polyposis (FAP) of the bowel, COX-2 inhibition has been shown to inhibit the development of invasive cancer and reduce the frequency of polyp formation [19-22]. A key study using 6 months of the selective COX-2 inhibitor Celecoxib, $400 \mathrm{mg}$ bd (twice the licensed anti-arthritis dose) showed a significant reduction in polyp formation compared with placebo [22]. Studies using Celecoxib in transgenic mice engineered to over-express HER-2/neu (an inducer of COX-2 expression) show reduced incidence of mammary tumours [23,24], and a reduction in metastatic potential [25]. Work from our laboratory [26] has demonstrated that Celecoxib prevents the growth of human breast tumour xenografts in a nude mouse model.

\section{Mechanism of action}

\section{Proliferation and apoptosis}

COX-2 expression is associated with high levels of cell proliferation $[7,27]$, but as yet no data have been published that show inhibition of COX-2 leads to reduced proliferation in vivo. Studies of transgenic mice engineered to over-express COX-2 have shown that these mice form mammary tumours earlier and more often than wild type mice, their mammary glands contain fewer apoptotic cells and show reduced expression of the pro-apoptotic proteins BAX and $\mathrm{BCl}-\mathrm{x}(\mathrm{L})$ [28]. COX inhibition has been shown to increase apoptosis by a number of varied mechanisms. COX-2 inhibition has been shown to decrease tumour burden and apoptosis in an in vivo model of spontaneous metastatic breast cancer [29] with reduced activation of the pro-apoptotic serine/ threonine kinase AKT, which is a key regulator of PI3Kinase mediated cell signalling. When AKT is phosphorylated it inhibits apoptosis by a variety of downstream effectors including phosphorylation of BAD (a Bcl-2 family member) and with a release of Bcl-2 family anti-apoptotic proteins which inhibit the mitochondrial death pathway. In a study investigating the effect of Celecoxib on prostate cancer cell lines, AKT phosphorylation was also shown to be significantly decreased following Celecoxib, leading to increased caspase-3 activation and apoptosis [11]. In colorectal cancer NSAIDs and COX-2 inhibitors have also proven to increase apoptosis. Again inactivation of AKT has been seen [30] as well as downregulation of the inhibitor of apoptosis protein (IAP) survivin [30] supression of NFKB [31] and accumulation of arachidonic acid (the COX substrate) [30] which via the generation of ceramide has been shown to increase apoptosis [32].

\section{Angiogenesis/lymphangiogenesis}

Celecoxib is known to be a potent anti-angiogenic agent. Over-expression of COX-2 leads to increased vascular endothelial growth factor receptor (VEGF) production [33] and publications from Dubois et al. have demonstrated that COX-2 inhibition leads to a reduction in VEGF [33-35]. Lung cancer xenografts show decreased vascularity when implanted into mice engineered to lack the expression of COX-2 [36]. In invasive breast cancer, COX-2 expression correlates with levels of angiogenesis (measured by CD-31 staining) [37] and lymph node metastasis [38] In normal mammary tissue COX-2 regulates angiogenesis via $\mathrm{PGE}_{2}$ production [9] and inhibition of angiogenesis by COX-2 inhibitors has a potential use in chemoprevention. A randomized trial using Celecoxib for 2 weeks before surgery, compared with no treatment, showed a fall in serum VEGF after 2 weeks of treatment and may be useful in preventing angiogenesis and lymphovascular spread in the peri-operative period [39].

As most breast cancers spread initially via the lymphatics, an important property of COX-2 inhibitors 
may be their ability to inhibit the formation of new lymphatic vessels (lymphangiogenesis). A study from our own laboratory suggests that, in addition to the ability of COX-2 to be an anti-angiogenic agent, it may also be a potent anti-lymphangiogenic factor [26].

\section{COX-2 independent effects}

A number of authors suggest that there are Cyclooxygenase independent effects of the COX inhibitors. In cell culture models NSAIDs have been shown to decrease proliferation and increase apoptosis of cells irrespective of whether they expressed the COX enzymes [40]. In addition derivatives of Celecoxib (the selective COX-2 inhibitor) which lack COX-2 inhibitory effects, maintain their ability to increase apoptosis [41]. The non-COX targets of the inhibitors have been suggested to include phosphodiesterases, the transcription factor $\mathrm{NF} K \mathrm{~B}$, the serine-threonine kinases -3-phosphoinositide-dependent kinase-1 (PDK1) and ribosomal S6 kinase-2 (RSK2), Ras, and the peroisome proliferative-activated receptors (PPAR) alpha, gamma and delta. The exact mechanisms of COX independent inhibition remain to be clarified in vivo.

\section{COX inhibitors in breast cancer: alone or in combination?}

Mounting pre-clinical evidence that COX-2 inhibition is a novel anti-cancer strategy prompted the formation of a number of Phase II and III clinical trials of its efficacy in patient populations. Following the recent controversy over COX-2 inhibitor class safety, a number of these trials have now closed to recruitment and trials that are continuing are not treating patients with COX-2 inhibitors for longer than 1 year. It is likely that, if COX inhibitors are introduced into clinical practice in the future that they will be used as combination therapy either with hormonal agents, such as an aromatase inhibitors (Als) or with growth factor receptor blockers, such as trastuzumab (Herceptin ${ }^{\circledR}$ ). COX-2 inhibitors have also been shown to enhance the chemo- [42,43] and radio-sensitivity of tumours [44].

$\mathrm{PGE}_{2}$ and cytokines, such as interleukin- 6 or TNF- $\alpha$, regulate aromatase activity in tumour cells $[45,46]$, there is a strong association between increasing COX-1 and COX-2 expression and the aromatase CYP19 gene expression in breast cancer [45]. In addition the $P G$ product of COX-2 activity, $\mathrm{PGE}_{2}$, markedly increases the presence of aromatase [47]. Therefore, blocking $\mathrm{PGE}_{2}$ using COX-2 inhibitors may inhibit aromatase activity and, when combined with Als, reduce tumour recurrence, enhancing the inhibition of a common target. The effects of this inhibition in vivo have been demonstrated in a rodent model by Pesenti et al. where they have shown that Celecoxib combined with exemestane significantly inhibits the growth of mammary tumours compared with control or Celecoxib alone [48], and results of a small, randomized, Phase II study of 111 post-menopausal women with advanced breast cancer treated with exemestane, $25 \mathrm{mg}$ qd, and Celecoxib, $400 \mathrm{mg}$ bd showed a longer time to recurrence (with no additional side-effects) following the use of Celecoxib and exemestane [49].

Blocking $\mathrm{PGE}_{2}$ production by inhibiting $\mathrm{COX}-2$ has been shown to result in decreased HER-2/neu protein levels [50]. Up to $80 \%$ of DCIS expresses COX-2 and its expression correlates strongly with expression of HER-2/neu [51,52]. It may therefore be beneficial to use COX-2 inhibition in combination with the monoclonal antibody to HER-2, trastuzumab $\left(\right.$ Herceptin ${ }^{\circledR}$ ). One Phase II randomized trial using trastuzumab, with or without Celecoxib, in metastatic breast cancer patients (who previously progressed after trastuzumab-based treatments) found that there was no tumour responses with the combination. Though the drug combination was well tolerated [53]. The effects on trastuzumab naive patients is not yet know.

In Lewis lung cancer models, co-administration of Celecoxib with Cyclophosphamide has proven significantly more effective in preventing tumour growth of than either drug alone [54] and studies using combinations of several chemotherapy agents with Celecoxib have indicated that Celecoxib lowers the threshold of sensitivity to chemotherapy $[42,43]$.

COX-2 is expressed in high levels in DCIS and there is interest in the use of COX-2 inhibitors to prevent recurrence of this pre-invasive disease and it is possible that combining COX-2 inhibition with an $\mathrm{Al}$ in DCIS patients will reduce recurrence in both the ipsilateral and contralateral breast. Early, placebocontrolled studies in DCIS are assessing the effects of 14 days of pre-operative Celecoxib on proliferation, apoptosis and angiogenesis. Given the lack of chemopreventive agents that can be used to prevent ER-negative breast cancer or used as adjuvant therapy in ER-negative breast cancer, there is a potential primary role for Celecoxib in this setting.

\section{Safety issues: an ongoing debate}

The recent withdrawal of Rofecoxib $\left(\right.$ Vioxx $\left.{ }^{\circledR}\right)$ from the market due to an increased risk of cardiovascular events high-lighted in the APPROVe trial [55] which confirmed previous evidence in the Vioxx Gastrointestinal Outcomes Research (VIGOR) trial [56] has brought the safety of other COX-2 inhibitors into question. The FDA in the United States has also recently recommended the withdrawl of another COX-2 inhibitor - Valdecoxib $\left(\right.$ Bextra $\left.^{\circledR}\right)$ from the market. The 
New England Journal of Medicine, recently published a review of Celecoxib cardiac safety. This raises concerns about the cardiac safety of prolonged and high dose COX-2 inhibition [57], and although a recent article by Kimmel et al. [58] suggested that patients who had been taking Rofecoxib had a three times greater risk of Myocardial infarction compared to patients taking Celecoxib, the jury is still out on the overall class safety.

With the accumulation of data suggesting that COX-2 inhibition is an exciting novel anti-cancer strategy, the use of this pathway as an anti-cancer strategy should continue to be investigated. However there may need to have obligate introduction of drug holidays during treatment, the use of drug combinations (as mentioned above) permitting lower-dose treatment, or indeed the development of new generation products, which either target COX-2, or permit other downstream factors of the pathways to be perturbed. This avenue is already being investigated with new classes of compounds targeting the AKT and Erk signalling pathways created by modifying existing cOX-2 inhibitor structures [59].

\section{Conclusions}

The results from pre-clinical studies suggest that COX-2 inhibition either alone or in combination with other therapeutic agents may be able to reduce overall disease recurrence and/or metastatic spread. And although the toxicity issues surrounding the COX-2 inhibitors remain to be fully clarified, data acquired from ongoing and now closed clinical trials are awaited with interest.

\section{References}

1. Hla T, Bishop-Bailey D, Liu CH, et al. Cyclooxygenase-1 and -2 isoenzymes. Int $J$ Biochem Cell Biol 1999; 31: $551-557$.

2. Fu JY, Masferrer JL, Seibert K, Raz A, Needleman P. The induction and suppression of prostaglandin $\mathrm{H} 2$ synthase (cyclooxygenase) in human monocytes. $J$ Biol Chem 1990; 265: 16737-16740.

3. Xie WL, Chipman JG, Robertson DL, Erikson RL, Simmons DL. Expression of a mitogen-responsive gene encoding prostaglandin synthase is regulated by mRNA splicing. Proc Natl Acad Sci USA 1991; 88: 2692-2696.

4. O'Neill GP, Ford-Hutchinson AW. Expression of mRNA for cyclooxygenase-1 and cyclooxygenase-2 in human tissues. FEBS Lett 1993; 330: 156-160.

5. Smith WL, DeWitt DL, Garavito RM. Cyclooxygenases: structural, cellular, and molecular biology. Annu Rev Biochem 2000; 69: 145-182.

6. Herschman H. Prostaglandin synthase 2. Biochem Biophys Acta 1996; 1299: 125-140.

7. Boland GP, Butt IS, Prasad R, Knox WF, Bundred NJ. COX-2 expression is associated with an aggressive phenotype in ductal carcinoma in situ. Br J Cancer 2004; 90: 423-429.
8. Gasparini G, Longo R, Sarmiento R, Morabito A. Inhibitors of cyclo-oxygenase 2: a new class of anticancer agents? Lancet Oncol 2003; 4: 605-615.

9. Chang SH, Liu CH, Conway R, et al. Role of prostaglandin E2-dependent angiogenic switch in cyclooxygenase 2induced breast cancer progression. Proc Natl Acad Sci USA 2004; 101: 591-596.

10. Kirkpatrick K, Ogunkolade W, Elkak AE, et al. The association between cyclooxygenase-2 expression and cell proliferation and angiogenesis in human breast cancer. Breast Cancer Res 2001; 3: A37.

11. Hsu AL, Ching TT, Wang DS, et al. The cyclooxygenase2 inhibitor celecoxib induces apoptosis by blocking Akt activation in human prostate cancer cells independently of Bcl-2. J Biol Chem 2000; 275: 11397-11403.

12. Ristimaki A, Sivula A, Lundin J, et al. Prognostic significance of elevated cyclooxygenase-2 expression in breast cancer. Cancer Res 2002; 62: 632-635.

13. Barnes NL, Boland GP, Cramer A, Knox WF, Bunderd NJ. Recurrence of ductal carcinoma in situ: the role of COX-2 expression. Br J Surg 2004; 91(S1): 37 [Abstract 2].

14. Vane JR. Inhibition of prostaglandin synthesis as a mechanism of action for aspirin-like drugs. Nat New Biol 1971; 231: 232-235.

15. Hawkey CJ. COX-2 inhibitors. Lancet 1999; 353: 307-314.

16. Kurumbail RG, Stevens AM, Gierse JK, et al. Structural basis for selective inhibition of cyclooxygenase-2 by anti-inflammatory agents. Nature 1996; 384: 644-648.

17. Hinz B, Brune K. Cyclooxygenase-2 - 10 years later. $J$ Pharmacol Exp Ther 2002; 300: 367-375.

18. Harris RE, Chlebowski RT, Jackson RD, et al. Breast cancer and nonsteroidal anti-inflammatory drugs: prospective results from the Women's Health Initiative. Cancer Res 2003; 63: 6096-6101.

19. Giardiello FM, Hamilton SR, Krush AJ, et al. Treatment of colonic and rectal adenomas with sulindac in familial adenomatous polyposis. N Engl J Med 1993; 328: 1313-1316.

20. Steinbach G, Lynch PM, Phillips RK, et al. The effect of celecoxib, a cyclooxygenase-2 inhibitor, in familial adenomatous polyposis. N Engl J Med 2000; 342: 1946-1952.

21. Asano TM, McLeod RS. Non-steroidal anti-inflammatory drugs and aspirin for the prevention of colorectal adenomas and cancer: a systematic review. Dis Colon Rectum 2004; 47: 665-673.

22. Phillips RK, Wallace MH, Lynch PM, et al. A randomised, double blind, placebo controlled study of celecoxib, a selective cyclooxygenase 2 inhibitor, on duodenal polyposis in familial adenomatous polyposis. Gut 2002; 50: 857-860.

23. Howe LR, Subbaramaiah K, Patel J, et al. Celecoxib, a selective cyclooxygenase 2 inhibitor, protects against human epidermal growth factor receptor 2 (HER-2)/neuinduced breast cancer. Cancer Res 2002; 62: 5405-5407.

24. Lanza-Jacoby S, Miller S, Flynn J, et al. The cyclooxygenase-2 inhibitor, celecoxib, prevents the development of mammary tumors in Her-2/neu mice. Cancer Epidemiol Biomarkers Prev 2003; 12: 1486-1491.

25. Roche-Nagle G, Connolly EM, Eng M, Bouchier-Hayes DJ, Harmey JH. Antimetastatic activity of a cyclooxygenase-2 inhibitor. Br J Cancer 2004; 91: 359-365.

26. Barnes NLP, Warnberg F, Farnie G, Jiang W, Anderson E, Bundred NJ. Cyclooxygenase-2 inhibition induces apoptosis via PKB pathway and reduces lymphangiogenesis. Breast Cancer Res Treat 2004; 88: S71. 
27. Ferrandina G, Ranelletti FO, Lauriola L, et al. Cyclooxygenase-2 expression in lymph node metastasis of cervical and vulvar cancer. Oncol Rep 2003; 10: 1799-1804.

28. Liu $\mathrm{CH}$, Chang SH, Narko K, et al. Overexpression of cyclooxygenase-2 is sufficient to induce tumorigenesis in transgenic mice. J Biol Chem 2001; 276: 18563-18569.

29. Basu GD, Pathangey LB, Tinder TL, et al. Cyclooxygenase-2 inhibitor induces apoptosis in breast cancer cells in an in vivo model of spontaneous metastatic breast cancer. Mol Cancer Res 2004; 2: 632-642.

30. Tuynman JB, Peppelenbosch MP, Richel DJ. COX-2 inhibition as a tool to treat and prevent colorectal cancer. Crit Rev Oncol Hematol 2004; 52: 81-101.

31. Grilli M, Pizzi M, Memo M, Spano P. Neuroprotection by aspirin and sodium salicylate through blockade of NFkappaB activation. Science 1996; 274: 1383-1385.

32. Chan TA, Morin PJ, Vogelstein B, Kinzler KW. Mechanisms underlying nonsteroidal antiinflammatory drug-mediated apoptosis. Proc Natl Acad Sci USA 1998; 95: 681-686.

33. Tsujii M, Kawano S, Tsuji S, et al. Cyclooxygenase regulates angiogenesis induced by colon cancer cells. Cell 1998; 93: 705-716.

34. Woods JM, Mogollon A, Amin MA, et al. The role of COX-2 in angiogenesis and rheumatoid arthritis. Exp Mol Pathol 2003; 74: 282-290.

35. Sawaoka H, Tsuji S, Tsuji M, et al. Cyclooxygenase inhibitors suppress angiogenesis and reduce tumor growth in vivo. Lab Invest 1999; 79: 1469-1477.

36. Williams CS, Tsujii M, Reese J, et al. Host cyclooxygenase2 modulates carcinoma growth. J Clin Invest 2000; 105: 1589-1594.

37. Davies G, Salter J, Hills M, et al. Correlation between cyclooxygenase-2 expression and angiogenesis in human breast cancer. Clin Cancer Res 2003; 9: 2651-2656.

38. Costa C, Soares R, Reis-Filho JS, et al. Cyclo-oxygenase 2 expression is associated with angiogenesis and lymph node metastasis in human breast cancer. J Clin Pathol 2002; 55: 429-434.

39. O'Donoghue GT, Roche-Nagle G, Connolly EM, et al. Selective COX-2 inhibition attenuates the perioperative increase iof the tumour enhancing proangiogenesis cytokine VEGF in human breast cancers. Br J Surg 2004; 91: 43S.

40. Zhang X, Morham SG, Langenbach R, Young DA. Malignant transformation and antineoplastic actions of nonsteroidal antiinflammatory drugs (NSAIDs) on cyclooxygenase-null embryo fibroblasts. J Exp Med 1999; 190: 451-459.

41. Song X, Lin HP, Johnson AJ, et al. Cyclooxygenase-2, player or spectator in cyclooxygenase-2 inhibitor-induced apoptosis in prostate cancer cells. J Natl Cancer Inst 2002; 94: 585-591.

42. Nakata E, Mason KA, Hunter N, et al. Potentiation of tumor response to radiation or chemoradiation by selective cyclooxygenase-2 enzyme inhibitors. Int $J$ Radiat Oncol Biol Phys 2004; 58: 369-375.

43. Altorki NK, Keresztes RS, Port JL, et al. Celecoxib, a selective cyclo-oxygenase-2 inhibitor, enhances the response to preoperative paclitaxel and carboplatin in early-stage non-small-cell lung cancer. J Clin Oncol 2003; 21: 2645-2650.

44. Milas L, Kishi K, Hunter N, et al. Enhancement of tumor response to gamma-radiation by an inhibitor of cyclooxygenase-2 enzyme. J Natl Cancer Inst 1999; 91: 1501-1504.
45. Brueggemeier RW, Quinn AL, Parrett ML, et al. Correlation of aromatase and cyclooxygenase gene expression in human breast cancer specimens. Cancer Lett 1999; 140: 27-35.

46. Michael MD, Michael LF, Simpson ER. A CRE-like sequence that binds CREB and contributes to CAMPdependent regulation of the proximal promoter of the human aromatase P450 (CYP19) gene. Mol Cell Endocrinol 1997; 134: 147-156.

47. Zhao Y, Agarwal VR, Mendelson CR, Simpson ER. Estrogen biosynthesis proximal to a breast tumour is stimulated by PGE2 via cyclic AMP, leading to activation of promotor II of the CYP19 (aromatase) gene. Endocrinology 1996; 137: 5739-5742.

48. Pesenti E, Masferrer JL, di Salle E. Effect of exemestane and celecoxib alone or in combination on DMBA-induced mammary carcinoma in rats. Breast Cancer Res 2001; 69: 288S [Abstract 445].

49. Dirix LY, Ignacio J, Nag S, et al. Final results from an open-label, multicenter, controlled study of exemestane $+/$ - celecoxib in postmenopausal women with advanced breast cancer (ABC) progressed on tamoxifen (T). Proc Am Soc Clin Oncol 2003; 22: 20 [Abstract 77].

50. Benoit V, Relic B, Leval XD, et al. Regulation of HER-2 oncogene expression by cyclooxygenase-2 and prostaglandin E2. Oncogene 2004; 23: 1631-1635.

51. Half E, Tang XM, Gwyn K, et al. Cyclooxygenase-2 expression in human breast cancers and adjacent ductal carcinoma in situ. Cancer Res 2002; 62: 1676-1681.

52. Tan KB, Yong WP, Putti TC. Cyclooxygenase-2 expression: a potential prognostic and predictive marker for high-grade ductal carcinoma in situ of the breast. Histopathology 2004; 44: 24-28.

53. Dang CT, Dannenberg AJ, Subbaramaiah K, et al. Phase II study of celecoxib and trastuzumab in metastatic breast cancer patients who have progressed after prior trastuzumab-based treatments. Clin Cancer Res 2004; 10: 4062-4067.

54. Koki AT, Leahy KM, Masferrer JL. Potential utility of COX2 inhibitors in chemoprevention and chemotherapy. Expert Opin Investig Drugs 1999; 8: 1623-1638.

55. Bresalier RS, Sandler RS, Quan H, et al. Cardiovascular events associated with refecoxib in a colorectal adenoma chemoprevention trial. N Engl J Med 2005; 352: 1092-1102.

56. Bomdardier C, Laine L, Reicin A, et al. Comparison of upper gastrointestinal toxicity of rofecoxib and naproxen in patients with rheumatoid arthrtis. N Engl J Med 2000; 343: 1520-1528.

57. Solomon SD, McMurray JJ, Pfeffer MA, et al. Adenoma prevention with celecoxib (APC) study investigators. Cardiovascular risk associated with celecoxib in a clinical trial for colorectal adenoma prevention. N Engl J Med 2005; 352: 1071-1080.

58. Kimmel SE, Berlin JA, Reilly M, et al. Patients exposed to rofecoxib and celecoxib have different odds of non fatal myocardial infarction. Ann Intern Med 2005; 142: 157-164.

59. Zhu J, Song X, Lin HP, et al. Using cyclooxygenase-2 inhibitors as molecular platforms to develop a new class of apoptosis-inducing agents. J Natl Cancer Inst 2002; 94: 1745-1757. 